\title{
PENINGKATAN KOMPETENSI OPERATOR PLTMH RIMBA LESTARI DI DUSUN TANGSI JAYA KECAMATAN GUNUNG HALU BANDUNG BARAT
}

\author{
Achmad Mudawari ${ }^{1}$, Djafar Sodiq ${ }^{1}$, I Made Wiwit K. ${ }^{1}$, Ahmad Deni M. ${ }^{1}$, Ali Mashar ${ }^{1}$, \\ Aceng Daud ${ }^{1}$, Hermagasantos Zein ${ }^{1}$, Siti Saodah ${ }^{1}$, Erwin Yusuf ${ }^{1}$ \\ ${ }^{1}$ Jurusan Teknik Konversi Energi, Politeknik Negeri Bandung \\ Email: achmad.mudawari@polban.ac.id
}

\begin{abstract}
Abstrak
PLTMH Rimba Lestari kapasitas $18 \mathrm{KW}$ terletak di Dusun Tangsi Jaya, Desa Gunung Halu, Kecamatan Gunung Halu, Kabupaten Bandung Barat, Provinsi Jawa Barat perlu dijaga untuk dapat tetap beroperasi dengan sehat guna memasok keperluan daya listrik warga masyarakat sekitar. Untuk itu diperlukan para operator mandiri yang memiliki pengetahuan dan keterampilan secara memadai. Oleh karena itu, pelatihan bagi operatornya merupakan langkah yang tepat untuk dilakukan. Paper ini dimaksudkan untuk melakukan kajian terhadap program pelatihan bagi para operator PLTMH yang dimulai dari survey penjajagan, penyusunan silabus dan metode pelaksanaannya hingga pengukuran efektivitas pelatihan yang dilaksanakan. Materi pelatihan meliputi teori dan praktek dengan instruktur yang berpengalaman sesuai dengan substansi yang dilatihkan. Dengan materi dan metode yang diterapkan Pelatihan dapat berjalan dengan lancar dan berhasil dengan baik. Dengan melihat latar belakang masalah peserta didik yang beragam dari tingkat pendidikan maupun pola pikir, perlu adanya pendekatan metoda dan materi yang tepat untuk melaksanakan kegiatan pelatihan ini. Keberhasilan ini ditunjukkan oleh partisipasi aktif dan semangat tinggi para peserta selama mengikuti pelatihan serta tingginya tingkat serapan terhadap materi/substansi pelatihan, yaitu meningkatnya pengetahuan dan keterampilan dalam mengoperasikan pembangkit dengan baik yang ditunjukkan dengan tingginya nilai hasil uji akhir (posttest). Selain itu, paper ini juga bisa digunakan sebagai rujukan bagi para pihak yang akan melakukan kegiatan serupa atau lainnya yang terkait dengan PLTMH.
\end{abstract}

Kata kunci: Operator, materi, metode dan sistem pendekatan.

\section{PENDAHULUAN}

Pembangkit Listrik Tenaga Mikro Hidro (PLTMH) adalah pembangkit listrik energi terbarukan skala kecil yang memanfaatkan aliran sungai dan beda ke- tinggian dengan daya tidak lebih dari $200 \mathrm{~kW}$. Umumnya PLTMH digunakan untuk memasok energi untuk daerah pedasaan yang belum terjangkau oleh jaringan Listrik PLN. 
DIFUSI

Volume 3, No.1 Januari 2020

Dusun Tangsi Jaya terletak di Desa Gunung Halu, Kecamatan Gunung Halu, Kabupaten Bandung Barat, Provinsi Jawa Barat. Desa ini termasuk desa yang memanfaatkan energi listrik dari PLTMH sejak tahun 2007. Wilayah Desa Gunung Halu berada pada ketinggian 1.100 meter dari atas permukaan laut (DPL), dengan bentang alam desa berada disekitar hutan dan topografi wilayah berbukit-bukit. Luas wilayah Desa Gunung Halu, secara keseluruhan adalah 3.869.63 hektar. Terdiri dari Terdiri dari 3 (tiga) dusun, dengan jumlah 24 Rukun Warga (RW) dan 80 Rukun Tetangga (RT). Desa Gunung Halu memiliki jumlah penduduk secara keseluruhan sekitar 10.437 orang dengan komposisi laki-laki 5.062 orang dan perempuan sebanyak 5.375 orang, sedangkan jumlah Kepala Keluarga adalah 2.748 KK. Perekonomian masyarakat Desa Gunung Halu masih tertumpu pada sektor pertanian dengan komposisi petani pemilik sebesar $57,87 \%$ buruh tani $24,64 \%$ dan buruh swasta sebesar $12,06 \%$.

Orbitasi Desa Gunung Halu sudah cukup baik walaupun jalan yang menghubungkan desa Gunung Halu dengan pusat-pusat kegiatan belum seluruhnya dilapisi aspal dan jembatan memadai, sehingga jalan yang menghubungkan desa Gunung Halu tidak dengan mudah dapat dilalui oleh kendaraan roda empat biasa. Jarak dari pusat desa Gunung Halu ke ibu kota negara Jakarta adalah $220 \mathrm{~km}$, sedangkan jarak ke ibu kota provinsi Bandung $80 \mathrm{~km}$, adapun jarak ke ibu kota kabupaten $60 \mathrm{~km}$ dan jarak ke ibu kota kecamatan adalah $3 \mathrm{~km}$.

Pembangunan PLTMH dimulai dengan kegiatan survei pada tahun 2006, dan di- bangun tahun 2007 dibiayai oleh APBD Provinsi Jawa Barat Tahun anggaran 2007 dengan masa konstruksi selama 3 bulan membangkitkan listrik sebesar 18 KW. Pada akhir tahun 2007 PLTMH selesai dibangun dan beroperasi melayani kebutuhan listrik masyarakat sebanyak 65 rumah dengan masing-masing memperoleh daya listrik sebesar 220 watt. Disamping itu PLTMH ini juga mensuplai 3 Mushola, 1 sekolah dan $2 \mathrm{Ru}-$ mah Dinas RPH.

Pada saat awal operasi PLTMH dioperasikan oleh beberapa operator yang mendapatkan pelatihan dari MHPP-GTZ. Seiring berjalannya waktu terdapat pergantian operator dari yang senior ke yang yunior. Namun operator yunior belum mendapatkan pelatihan sebagaimana halnya operator sebelumnya, sehingga mereka merasa mengalami kendala untuk mengoperasikan PLTMH tersebut.

Untuk menjamin keberlanjutannya maka dibentuklah lembaga pengelola PLTMH yang difasilitasi oleh MHPPGTZ sehingga saat ini telah memiliki lembaga pengelola PLTMH yang diberi nama KP-PLTMH RIMBA LESTARI. Lembaga ini bertanggung jawab terhadap pengoperasian dan perawatan PLTMH. Pembangkit ini merupakan andalan pemasok energi listrik bagi masyarakat sehingga perlu adanya keberlanjutan dan oleh karena itu dibutuhkan operator yang mempunyai kompetensi untuk mengoperasikan maupun perawatan. Gambar 1 memperlihatkan wilayah dukuh Tangsi Jaya Desa Gunung Halu. 


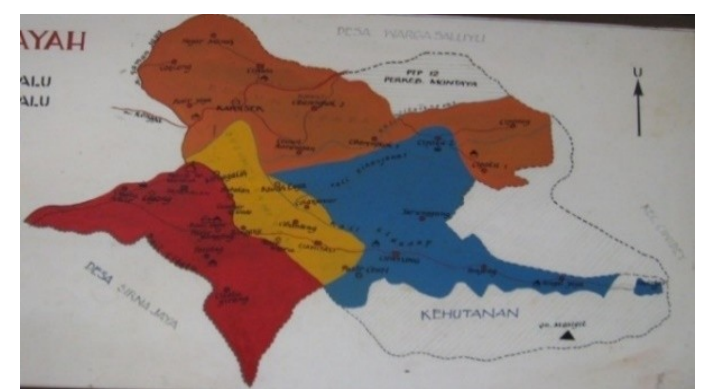

Gambar 1. Wilayah Desa Gunung Halu

Untuk menjaga agar PLTMH beroperasi dengan baik, salah satunya membutuhkan tenaga operator yang memiliki kemampuan mengoperasikan PLTMH secara memadai. Oleh karena itu, agar hal ini bisa berlanjut terus, maka di samping sistem peralatannya sehat, operatornya juga dalam keadaan siap.

PLTMH ini dibangun dan beroperasi pada tahun 2007. Awalnya pembangkit ini dioperasikan oleh beberapa operator yang mendapatkan pelatihan dari MHPP-GTZ. Seiring berjalannya waktu terdapat pergantian operator dari yang senior ke yunior, namun operator yunior belum mendapatkan pelatihan sebagaimana halnya operator sebelumnya. Kondisi ini mengakibatkan mereka merasa mengalami kendala untuk mengoperasikannya. Atas dasar itulah kegiatan pelatihan PLTMH yang berbasis pada masyarakat mandiri [1]. Paper ini dimaksukan untuk memberikan kajian terhadap bagaimana pelatihan ini diselenggarakan mulai dari persiapan, pelaksanaan sampai dengan pengukuran capaian pembelajarannya.

Instruktur dan guru yang berkualitas dan bermotivasi adalah kunci dari pembelajaran yang efektif [2]. Dalam pelatihan ini instrukturnya terdiri dari para dosen yang memiliki kualifikasi dan pengalaman sangat memadai terkait dengan topik pelatihan. Materi pelatihan dipilih yang benar-benar dibutuhkan oleh para peserta pelatihan. Untuk memberikan gambaran tentang substansi pelatihan, pada bagian ini akan disajikan informasi singkat tentang PLTMH Tangsi Jaya ini.

Secara prinsip PLTMH terdiri dari pipa air (penstock), turbin air, generator dan peralatan pendukung lainnya seperti pengatur tegangan (AVR) dan pengatur frekuensi yang menggunakan dummy load. Secara skematik prinsip PLTMH ditunjukkan pada Gambar 2 [3]. PLTMH dibuat mempunyai head (ketinggian) dan debit air konstan, sehingga daya potensial air yang masuk ke turbin (PinT) juga konstan. Dengan demikian daya masukan (poros) generator (PinG) juga akan konstan. Sementara itu, besar daya keluaran generator (PGen) yang disuplaikan ke beban (PBeban) akan selalu berubah sesuai dengan kebutuhan konsumen.

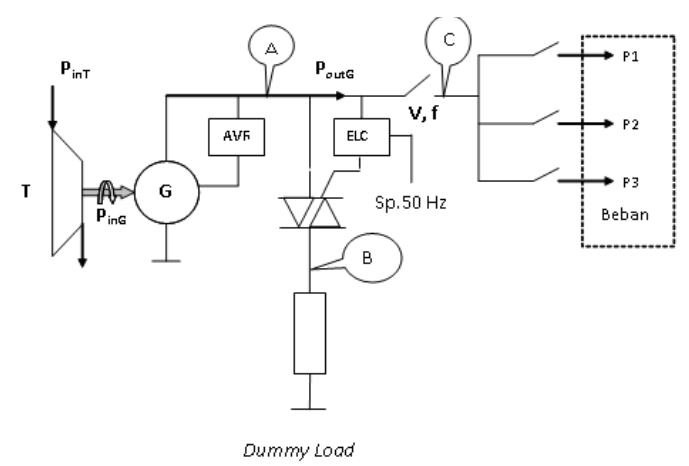

Gambar 2. Sistem PLTMH Tangsi Jaya

Automatic Voltage Regulator (AVR) bertindak sebagai penjaga tegangan keluaran generator, sedangkan untuk menjaga frekuensi agar tetap konstan pada PLTMH tidak menggunakan sistem governor sebagaimana pada pembangkitpembangkit besar karena tidak ekonomis. Untuk keperluan tersebut pada 
DIFUSI

Volume 3, No.1 Januari 2020

PLTMH yang menggunakan generator sinkron menggunakan Electronic Load Control (ELC).

Dari uraian di atas, menunjukkan bahwa sistem PLTMH tidaklah sederhana, khususnya bagi para operator lapangan yang pada umumnya masih awam terhadap teknologinya. Atas dasar itu, agar pelatihan bisa berjalan dengan efektif akan digunakan model pendekatan teoritis dan praktis. Pendekatan teoritis dilakukan dengan memberikan teori praktis yang menunang langsung pemahaman terhadap komponen-komponen utama sistem dan fungsinya.

Pada aspek teori PLTMH ini diuraikan juga tentang perlunya pengkajian yang menyeluruh termasuk pengukuran debit, studi kelayakan, perancangan dan pelatihan agar PLTMH dapat dibangun dan beroperasi sebagaimana mestinya [4-7]. Di sisi lain juga disampaikan perlu dilakukan evaluasi kinerja PLTMH dan jika mungkin dilakukan peningkatan kapasitas [8-9].

Sedangkan pendekatan praktisnya, peserta akan melakukan praktik langsung dari teori-teori yang telah diberikan termasuk praktik mengoperasikan PLTMH secara langsung. Dengan model pendekatan ini diharapkan peserta pelatihan mampu memahami sistem dan sekaligus mengoperasikannya sendiri. Agar tingkat penyerapan dari materi yang akan diberikan kepada peserta tinggi atau dengan kata lain tingkat keberhasilan sesuai dengan tujuan dari pelatihan ini, maka perlu dilihat latar belakang peserta baik dari sisi pendidikan maupun tingkat daya pikir peserta. Untuk itu perlu dilihat dari metode pela- tihan yang diberikan. Pemilihan metode dilandasi oleh aspek yang akan dicapai yaitu Aspek Afektif, Kognitif dan Psikomotorik dari peserta. Maka perlu dijelaskan batasan istilah yang terkandung dalam judul tersebut:

\section{Pelaksanaan}

Pelaksanaan Pelatihan yaitu proses, cara, pelaksanaan (rancangan dan keputusan). Adapun pelaksanaan yang dimaksud dalam pelatihan ini adalah suatu kegiatan yang dilakukan oleh pemberi pelatihan, apakah sudah melakukan bimbingan aspek afektif, kognitif dan psikomotorik. Dalam proses kegiatan pelatihan ini bertujuan untuk memiliki pengetahuan, sikap yang baik dan memiliki keterampilan dalam segi pengoperasian pembangkit PLTMH.

\section{Pelatihan}

Yang dimaksud dengan "pelatihan" adalah suatu proses kegiatan belajar/pendidikan yang dilaksanakan secara non formal yang tidak memiliki aspek tuntutan legalitas. Namun dari hasil pelatihan ini akan mendapatkan pengetahuan dan keterampilan yang akan langsung diterapkan pada bidang kerjanya yaitu untuk mengoperasikan pembangkit dengan benar. Pelatihan ini sifatnya memberikan bimbingan yaitu membantu peserta pelatihan dalam menyelesaikan masalahmasalah pada saat mengoperasikan pembangkit PLTMH Tangsi Jaya yang menyangkut aspek afektif, kognitif dan psikomotorik.

Dalam pelatihan ini dititikberatkan yang utama pada aspek Psikomotorik. Aspek 
DIFUSI

Volume 3, No.1 Januari 2020

psikomotorik merupakan aspek yang berkaitan dengan keterampilan (skill).

\section{METODE}

Metode pelaksanaan pengabdian kepada masyarakat (PKM) yang dilaksanakan berasal dari hasil analisis situasi yang dijumpai dan disepakati oleh masyarakat sebagai bentuk solusi yang ditawarkan. Tahapan kegiatan PKM diawali dengan survei lokasi, koordinasi dengan mitra, studi literatur kemudian dilanjutkan dengan persiapan alat dan bahan, pembuatan modul pelatihan, dan pelaksanaan pelatihannya.

Untuk mencapai tujuan pelatihan disusun dan disepakati metode pelatihannya sebagai berikut:

a. Pretest

Pretest dilakukan di awal pelatihan. Pretest ini dimaksudkan untuk mengetahui pemahaman dasar dari para peserta terhadap substansi pelatihan.

b. Ceramah dan diskusi

Ini merupakan proses penyampaian materi yang telah dirancang dan mendiskusikan permasalahan-permasalahan yang muncul. Lebih mengedepankan interaktifnya.

c. Praktek

Pada tahap ini, peserta dilibatkan secara langsung dalam mempraktikkan konsep-konsep yang telah dibahas dalam teori menggunakan modul-modul yang telah disiapkan termasuk instrumen-instrumen ukurnya.

d. Postest

Ini merupakan langkah terakhir dalam pelatihan ini, yaitu pengukuran terhadap capaian pembelajaran sehingga dapat diketahui efektivitas pelatihan.

Adapun materi yang disampaikan meliputi

a. Komponen utama dan bantu PLTMH

b. Pengoperasian PLTMH

c. Sistem kelistrikan

d. Praktik pengoperasian PLTMH

e. Praktik Sistem kelistrikan

Bobot pengelompokan bobot materi pelatihan jika ditinjau dari segi ketiga aspek yang ingin dicapai adalah sebagai berikut :

a. Aspek Psikomotorik antara lain pada materi Praktik pengoperasian pembangkit, praktik sistim kelistrikan, pengoperasian PLTMH dengan bobot nilai $65 \%$

b. Afektif dan kognitif pada materi komponen utama dan bantu PLTMH serta sistem kelistrikan dengan bobot nilai $35 \%$

Keseluruhan materi tersebut selaras dengan Peraturan Menteri ESDM No. 6 tahun 2008 sub bidang operasi dengan kode unit KTL. PO. 21.205.02. [10]. Di sisi lain kegiatan ini juga untuk memenuhi ketentuan keselamatan ketenagalistrikan sebagaimana diamanatkan dalam UU. RI No. 30 tahun 2009 khususnya Bab X pasal 44 ayat 1 dan 2. [11].

\section{HASIL DAN PEMBAHASAN}

Untuk melakukan evaluasi terhadap keberhasilan pelatihan yang ditetapkan dapat dilihat antara lain dari hasil evaluasi yang dilakukan melalui pretest dan 
postest. Gambar 3 dan 4 berturut-turut menampilkan hasil evaluasi pretest dan postest terhadap peserta pelatihan yang berjumlah 15 orang yang mengikuti kegiatan dari awal hingga akhir. S1 merupakan identifikasi dari peserta ke 1 dan S15 merupakan identifikasi dari peserta yang ke 15 .

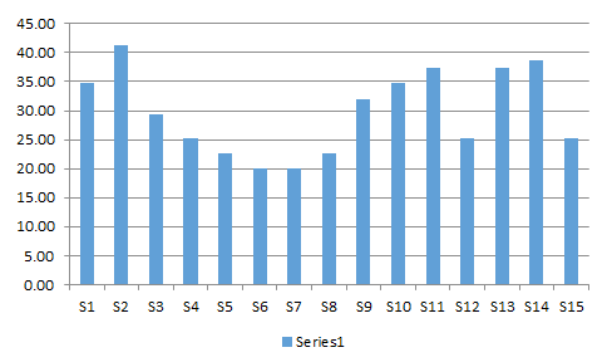

Gambar 3. Hasil evaluasi pretest

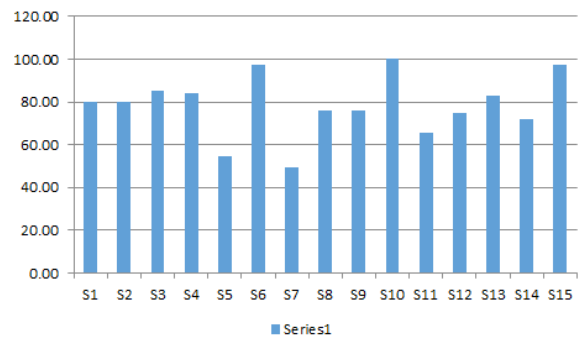

Gambar 4. Hasil evaluasi postest

Ada kenyataan yang cukup menarik jika dicermati dari hasil nilai pretest dan posttest. Untuk pretest nilai terendah adalah 20 dan tertinggi adalah 41 dengan nilai rata-rata 30,1 dari skala $0-100$. Sedangkan untuk postest nilai terendah adalah 49,33 dan nilai tertinggi adalah 100 dengan nilai rata-rata sebesar 76,95. Angka-angka ini menunjukkan bahwa pengetahuan dan keterampilan peserta sebelum dilakukan pelatihan sangat kurang, hal ini sesuai dengan informasi yang diperoleh melalui wawancara langsung dengan pengelola PLTMH yang menyatakan bahwa pengetahuan dan keterampilan para operator kurang sehingga perlu diadakan pelatihan untuk meningkatkan kompetensinya. Dengan memperhatikan nilai peserta setelah dilakukan pelatihan yang meningkat secara signifikan, berarti menunjukkan adanya peningkatan pengetahuan dan keterampilan. Perlu diungkapkan pula bahwa penyampaian materi baik teori maupun praktik dilakukan secara rileks dan tidak terlalu formal. Hal ini membuktikan bahwa metode yang dipilih dalam pelatihan ini sangat efektif.

Ini bisa menjadi bagian pembelajaran bagi para instruktur yang notabene juga dosen Polban tidak ada salahnya bila menerapkan metode semacam ini di lingkungan kampus yang terkenal terlalu serius dan kaku. Gambar 5 berikut menunjukkan ilustrasi visual model pembelajaran yang diterapkan pada pelatihan ini.

Gambar-gambar tersebut memper suasana kegiatan pelatihan yang berupa ceramah dan diskusi serta praktik. Kegiatan ceramah dan diskusi dilaksanakan di dalam ruangan untuk membahas beberapa hal yang berhubungan dengan teori-teori praktis PLTMH dan sistem kelistrikannya antara lain meliputi komponen, pengoperasian termasuk tata cara setting pembebanan dan juga yang berhubungan perawatan. Sedangkan kegiatan praktek keterampilan kelistrikan dilaksanakan di luar ruangan tepatnya di teras rumah dan khusus untuk PLTMH dilaksanakan secara langsung di PLTMH yang berlokasi di tengah persawahan dengan materi pengenalan komponen, perawatan, cara menjalankan serta setting pengaturan beban secara online. 
DIFUSI

Volume 3, No.1 Januari 2020
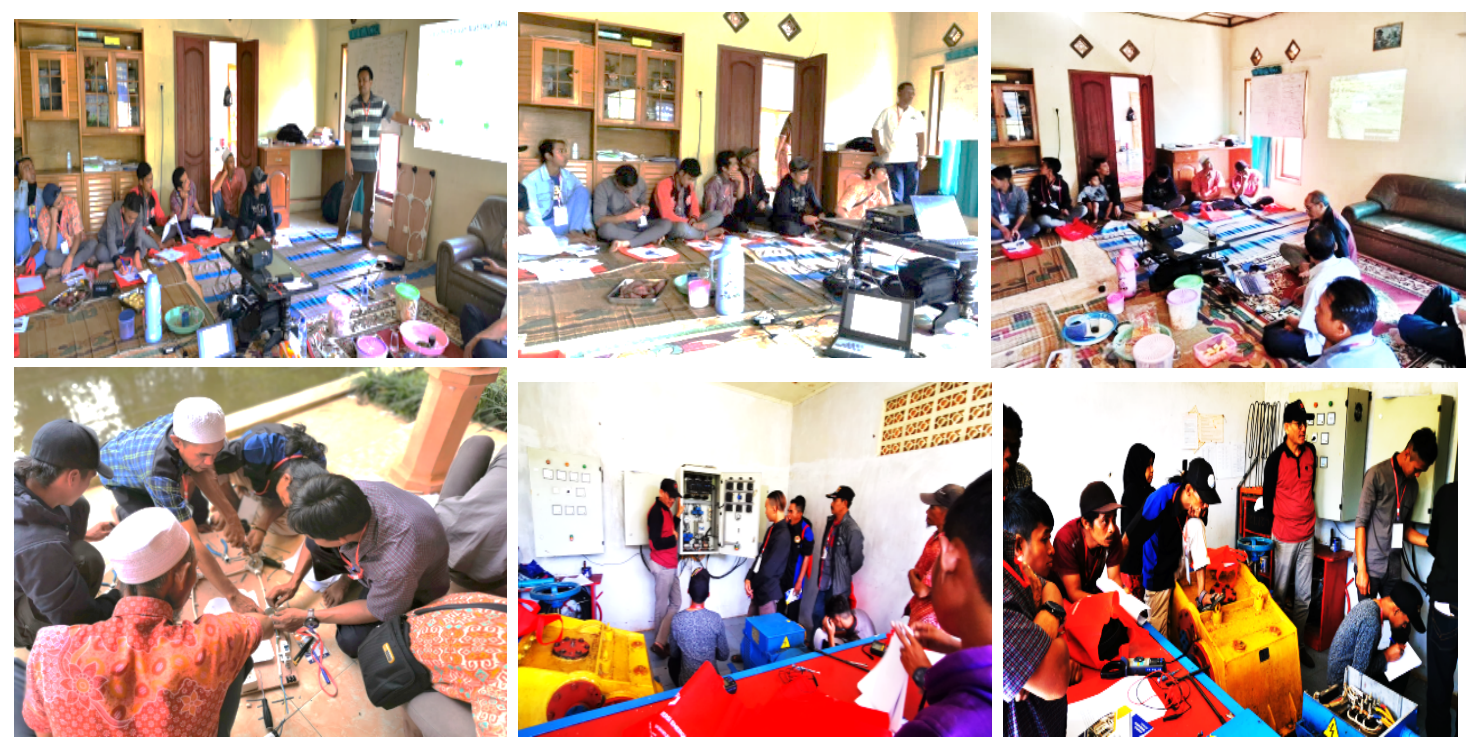

Gambar 5. Kegiatan Pelatihan

\section{KESIMPULAN}

Kegiatan pelatihan berjalan lancar sesuai dengan yang direncanakan. Metode dan model pendekatan yang diterapkan sangat tepat yang ditunjukkan terjadinya interaksi aktif dari para peserta selama pelatihan dan tingginya peningkatan pengetahuan dan kerampilan peserta dalam pengoperasian PLTMH. Ini menunjukkan bahwa kegiatan ini berhasil dengan baik.

\section{REFERENSI}

[1] D. Patabang dan T. Pagasis. Pelatihan Pengembangan PLTMH berbasis Masyarakat Mandiri, Jurnal Pengabdian Papua, Vol. 1, 2017.

[2] Bunning, TVET Teacher Education Curriculum, The Third International Conference on Innovation in Engineering and Vocational Education (ICIEVE), 2019.
[3] A. Mashar dan D. Sodiq, Analisis Harmonisa dari Electronic Load Control (ELC) pada PLTMH, SNP2M-PNJ, 2011.

[4] A. Susatyo dan R. A. Subekti, Implementasi Teknologi Pembangkit Listrik Tenaga Mikrohidro Kapasitas $30 \mathrm{KW}$ di Desa Cibunar Kabupaten Tasikmalaya Jawa Barat, Prosiding Seminar Nasional Daur Bahan Bakar. Serpong, 13 Oktober, 2009.

[5] S. Sukamto dan A. Kusmantoro. Perencanaan Pembangkit Listrik Tenaga Mikro Hidro (PLTMH) Jantur Tabalas Kalimantan Timur, Jurnal Teknik Elektro, Vol. 5. No. 2, 2013.

[6] V. Oktanti, P. T. Juwono, P. Hadi Wicaksono. Studi Perencanaan Pembangkit Listrik Tenaga Mikro Hidro (PLTMH) Desa Cikeusik Kecamatan Cidahu Kabupaten $\mathrm{Ku}-$ 
ningan Provinsi Jawa Baratm, 2017.

[7] Peraturan Menteri Energi dan Sumber Daya Mineral Republik Indonesia No 33 tahun 2014 tentang tingkat mutu pelayanan dan biaya yang terkait dengan penyaluran tenaga listrik oleh PT Perusahaan Listrik Negara (PERSERO), 2014.

[8] F. M. Pratama, Evaluasi Kinerja Pembangkit Listrik Tenag Mikrohidro Bantal pada pabrik Gula Asembagus kabupaten Situbonda, publikasi jurnal skripsi, Universitas Brawijaya, 2014.
[9] Rimbawati, A. A. Hutasusu, dan Muharni, Peningkatan Kapasitas Daya Listrik pada Pembangkit Listrik Tenaga Mikrohidro Bintang Asih guna memenuhi kebutuhan Penerangan, Jurnal unimed, Vol. 4, No. 4, 2018.

[10]Peraturan Menteri ESDM No. 6 tahun 2008 tentang Standard Kompetensi Tenaga Teknik Ketenaga listrikan Bidang Pembangkit tenaga Listrik, 2008.

[11]UU RI N0.30 tahun 2009 Tentang Ketenagalistrikan, 2009. 